\title{
Trends in adolescent smoking initiation in the United States: is tobacco marketing an influence?
}

\author{
Elizabeth A Gilpin, John P Pierce
}

\begin{abstract}
Objective-To compare recent trends in smoking initiation by adolescents with trends in inflation-adjusted cigarette pricing and tobacco marketing expenditures.

Design-We examined smoking initiation trends in demographic subgroups of adolescents aged 14-17 years during the decade 1979-1989. Data on cigarette pricing and tobacco marketing expenditures were adjusted for inflation and plot-
\end{abstract} ted over this same period.

Setting-Large population surveys, United States.

Subjects-140 975 ever-smokers aged 17-38 when surveyed in 1992 or 1993, who reported on age of smoking initiation during the decade 1979-1989.

Main outcome measure-Initiation rate was calculated as the number in an age group who reported starting to smoke regularly in a year, divided by the number of never-smokers at the start of the year. Trends were evaluated by linear and quadratic models.

Results-From 1979 to 1984, adolescent initiation rates decreased, but increased thereafter, particularly among males, whites, and those who, as adults, reported never having graduated from high school. Cigarette price increased throughout the decade as did tobacco marketing expenditures, especially for coupons, value-added items, and promotional allowances.

Conclusion-Availability of cheaper cigarettes is not likely to be a cause of increased smoking initiation by adolescents. Although other influences cannot be ruled out, we suspect that the expanded tobacco marketing budget, with its increased emphasis on tactics that may be particularly pertinent to young people, affected adolescent initiation rates.

(Tobacco Control 1997;6:122-127)

Cancer Prevention and Control Program, Cancer Center, University of California, San Diego, La Jolla, California, USA

E A Gilpin

J P Pierce

Correspondence to

Dr J P Pierce, UCSD Cancer Prevention and Control Program, Cancer Center 0901, 9500 Gilman Drive, La Jolla, California 92093-0901, USA; email: jppierce@ucsd.edu
Keywords: adolescents, smoking initiation, tobacco marketing

\section{Introduction}

The slow rate of decline in smoking prevalence in developed countries is strongly related to the persistent recruitment of new smokers. ${ }^{1-4}$ Over the past 30 years, the public health movement has been very successful in convincing adults not to start smoking, but adolescents remain a challenge. ${ }^{356}$ Public health programmes smoking must play against opposing infludesigned to influence young people not to start ences, such as the more than $\$ 6$ billion that the tobacco industry spent in 1993 to market its of products in the United States.

In the context of public health action to restrict the tobacco industry's marketing $\stackrel{\omega}{\stackrel{\omega}{*}}$ activities, it would be useful to investigate the $\vec{\rho}$ possible association between increased tobacco os marketing and increased smoking initiation by adolescents. Such an investigation requires $N$ appropriate surveillance of adolescent smok- $\stackrel{\circ}{?}$ ing. The most common measure of smoking $\overrightarrow{ }$ activity by adolescents relies on self-reporting the smoking of a cigarette in the past month. ${ }^{3}$ Both positive and negative responses pose interpretative difficulties with respect to the rate of adolescent smoking. A young person who eventually becomes an addicted smoker may be in a pre-experimentation stage or in an intermittent period of abstinence when surveyed, or an individual labelled as a smoker may be one of the approximately $30 \%$ of new experimenters who do not proceed to becoming addicted smokers. ${ }^{8}$ Complicating this issue is the tendency (in some settings) for adolescents to exaggerate or deny any cigarette use.

In the light of these difficulties, we have developed a measure of the incidence of smoking initiation that is based on recall by adults who became established regular smokers. ${ }^{510}$ This measure, computed from the age at which smokers or former smokers recall having started smoking regularly, appears to be insensitive to the age of the respondent when surveyed, ${ }^{5}$ and has proved useful for examining age- and gender-specific trends over time in smoking initiation among both adults and adolescents. ${ }^{5910}$ From this work, we determined that, in 1980 , initiation of regular smoking was greatest among adolescents aged 14-17 years, ${ }^{9}$ or alternatively, that this age range is when most smokers start smoking regularly.

This study uses more recent data to examine trends in rates of smoking initiation among demographic subgroups of adolescents, aged 14-17 years, throughout the 1980 s. As in another report documenting an increase in initiation for this group as a whole, ${ }^{6}$ initiation rates were calculated from the continuous Current Population Survey, which included a smoking supplement during selected months in 1992 and 1993. In addition, we present trends over this period in inflation-adjusted cigarette pricing and in the tobacco industry's budget for marketing. We then comment on the temporal association of these trends. 


\section{Methods}

\section{DATA SOURCES}

Initiation of regular smoking

We combined data from three recent Current Population Surveys (September 1992, January 1993, and May 1993) that contained a special supplement on tobacco use. The Current Population Surveys are continuously conducted by the US Census Bureau for labour force monitoring; they cover the civilian, non-institutionalised population aged 15 years and older. ${ }^{11}$ The Current Population Survey typically surveyed about 56000 households each month, in which interviews were conducted with a knowledgeable household member who responded for all eligible household members. About a quarter of all interviews were conducted in person; the remainder were conducted by telephone. For the tobacco use supplement, the Current Population Survey included intensive telephone follow-up efforts to maximise the proportion of respondents who completed the supplement. Response rates for the tobacco use supplement were $88.5 \%, 89.1 \%$, and $86.1 \%$ for September, January, and May, respectively.

Supplement respondents were asked, "Have you smoked at least 100 cigarettes in your entire life?" Those who responded "yes" were asked, "How old were you when you started smoking cigarettes fairly regularly?" We restricted our present analysis to selfrespondents who were 17-38 years old when surveyed $(n=140975)$. Such people would have been in the age range 14-21 years at some time during the decade 1979 to 1989 .

The public-use data tape for these three surveys includes a weighting variable for self-respondents which ensures that estimates from the combined sample will be representative of the US population by gender, age, race/ethnicity, and region. Subjects were identified only by a number on the public-use tape, so there is no way to link responses to individuals.

\section{Cigarette price and tobacco marketing data}

The Tobacco Institute publishes the weighted average price per pack of cigarettes at the state level and for the nation, as of 1 November each year. $^{12}$

Data on tobacco marketing expenditures are from the US Federal Trade Commission (FTC). ${ }^{7}$ Tobacco companies are required to report their expenditures on an annual basis, and the FTC reports categories for different types of expenditures: newspapers, magazines, outdoor, transit, point of sale, promotional allowances, sampling distribution, specialty item distribution, public entertainment, and all other. Starting in 1988, the coupons and retail value added category was added. Promotional programmes initiated that year by the tobacco industry allow individuals to redeem coupons obtained from cigarette purchases for specialty items. The value-added aspect of the new line item refers to multiple pack offers (buy two, get one free) and gifts of items, such as key chains or lighters with the purchase of cigarettes at the point of sale. Inspection of the category totals reported in 1987 and earlier indicated that this new category encompassed most of what was previously included in the specialty item distribution and all other categories, as the expenditures recorded for these $\overline{\bar{O}}$ categories dropped dramatically in 1988.

For our analysis, we combined $\overrightarrow{\overrightarrow{\vec{B}_{j}}}$ amounts for newspapers, magazines, outdoor (\$illboards), and transit (signs in and around putic transit) into a category for traditional pring-media. We also examined the promotional $\stackrel{\Phi}{\complement}$ allowances category, which includes incentives given to wholesalers and retailers to stock and promote a particular product, including trade allowances (free goods or price rectuctions in return for buying a specific quantif of goods) and slotting allowances (fees to retailers to carry a new product or âblocate premium shelf space to a given produ $\overrightarrow{g t}$ ). Finally, we combined the categories for sfecialty item distribution, which refers to itens such as teeshirts, caps, and sporting equipment that are imprinted with a brand's logo, foupons and retail value added, and all other into a category designated promotional items.

$\overrightarrow{0}$

Both the price of a pack of cigarettes and the total tobacco industry marketing e\&penditures were adjusted to 1989 dollars b using the annual Consumer Price Index (CIF) from the Bureau of Labor Statistics. ${ }^{13}$

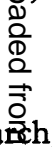

CALCULATION OF INITIATION RATES $\overrightarrow{\vec{\prime}}$

As described in previous reseach, 5910 we reconstructed each respondent'尔 smoking status for each year, starting with 1.79 through 1989 , from the age at which an sver-smoker reported starting to smoke regularly. Neversmokers were considered to be at gisk to start smoking throughout the period, smokers were at risk only throughthe year in which they started. The denominâtor for the initiation rate for a demographic group of interest was the sum of the weights for those in the group at risk to start smoking in a given year. The numerator was the sum of the weights of those whose reported age of starting to smoke indicated they started that year. Previously, we have shown that the of the respondent when surveyed had to apparent effect on the age the respondent reported for when regular smoking commenced. ${ }^{5}$ We computed initiation rates for $14 \frac{1}{7}$-year-old males and females, for blacks and whites, and according to attained educationaf level. For educational level, we did nof compute initiation rates for 1989, because some respondents were still high-sch when surveyed, and it was not known whether they would graduate or go on to codlege.

\section{STATISTICAL ANALYSIS}

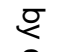

The initiation rates were multip fied by the actual sample size at a given year tetermine a pseudo-numerator, and then $95 \%$ binomial confidence intervals were computed in the usual manner. ${ }^{14}$

When we examined the plot of initiation rates over the decade for 14-17-year-olds, it appeared that a simple linear fit would not 
adequately represent the data; there appeared to be an inflection point near the middle of the decade. Thus, we fitted both linear and quadratic models to the initiation rates. We weighted each rate by the inverse of its standard error in these analyses, and plotted the model (linear or quadratic) that best fitted the data together with the yearly initiation rates and their $95 \%$ confidence intervals. In the text below, we report probability values for determining whether the relevant model coefficients are different from zero.

\section{Results}

INITIATION RATE TRENDS IN DEMOGRAPHIC SUBGROUPS

A pattern of a decline in the first half of the decade (which was reversed in the second half) was observed both in males, and to a lesser extent, in females (figure 1). The quadratic fit for males showed an improvement $(P=0.020)$ compared with the linear fit $(P=0.103)$. For females, neither the linear model $(P=0.943)$ nor the quadratic one $(P=0.102)$ produced significant coefficients, although the quadratic

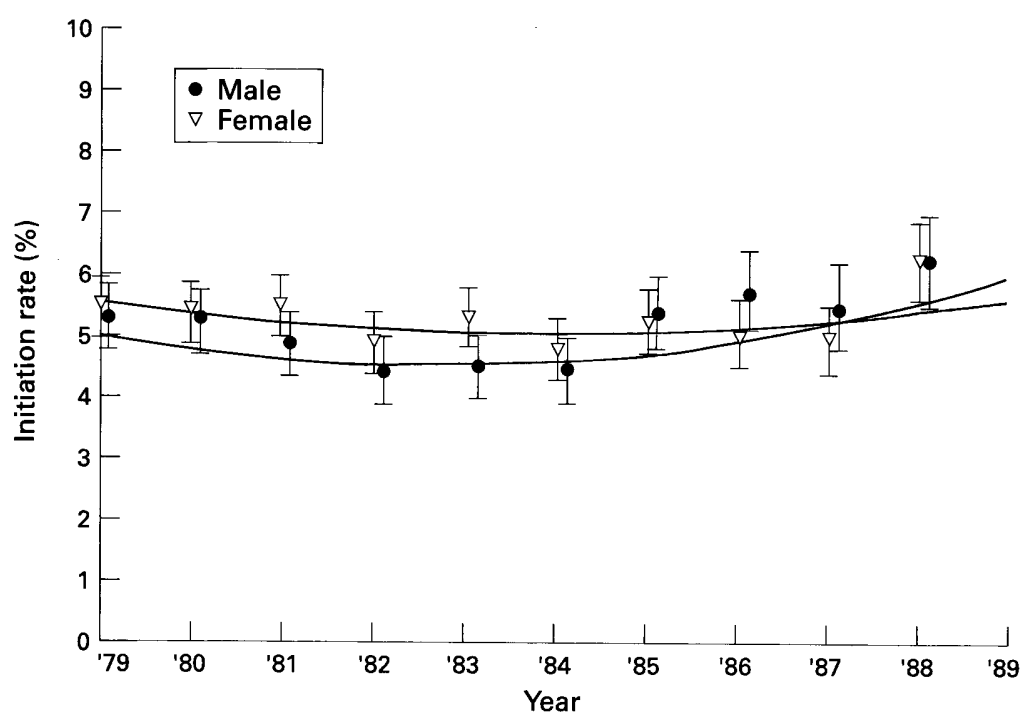

Figure 1 Initiation rates in male and female adolescents aged 14-17 years.

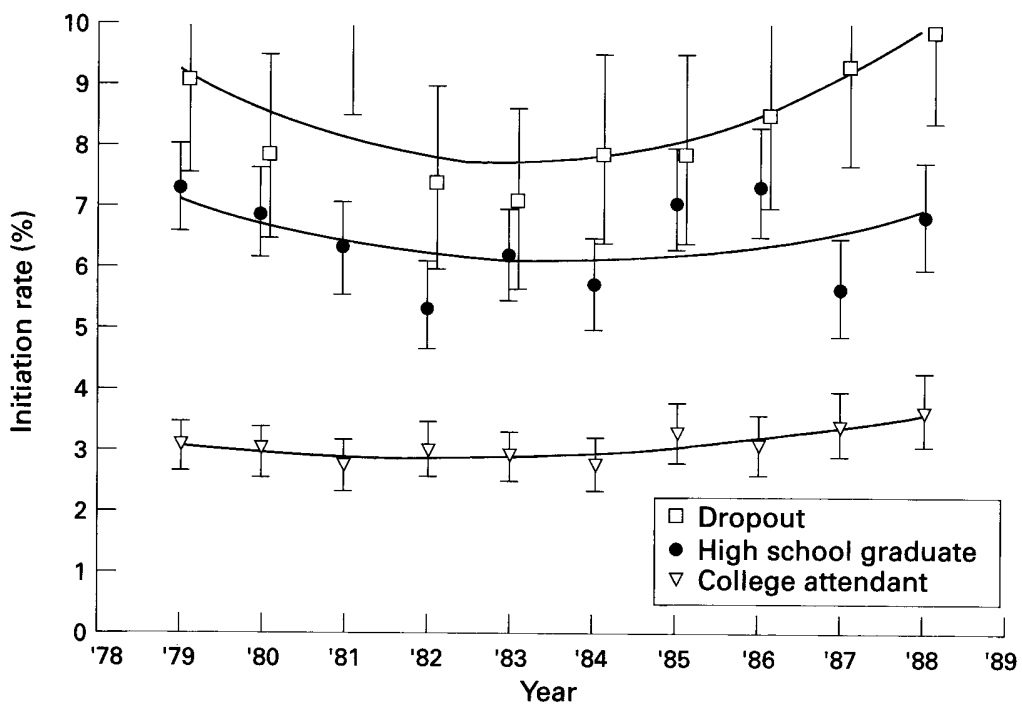

Figure 2 Initiation rates in respondents reporting less than 12 years of education, 12 years with no college education, and more than 12 years with some college education as adults. Rates are for the adolescent years (ages $14-17$ years) of these adult respondents. model came closer. By 1989, the incidence rate among males was $5.8 \%$ compared with a rate of $5.3 \%$ in females.

Initiation was highest among high school $\Omega$ dropouts and lowest among those who eventu- 을 ally attended college (figure 2). Quadratic $\overrightarrow{\overrightarrow{0}}$ models performed better than linear ones for all three educational groups. For high-school graduates, however, neither model produced 0 significant regression coefficients. For drop- 흘 outs, the significance of the linear coefficient in $\frac{\bar{\omega}}{\vec{D}}$ the linear model was $P=0.562$, and for the $\stackrel{\mathbb{Q}}{\Omega}$ quadratic term of the quadratic model, it was $\mathbf{P}=0.035$. For high-school graduates, these $\overrightarrow{0}$

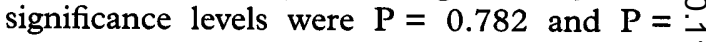
0.184 , and for those with some college they $\vec{\omega}$ were $P=0.081$ and $P=0.014$. In 1988 , the $\stackrel{\rho}{P}$ rate of initiation was $9.9 \%$ for those who did o not graduate from high school, $6.9 \%$ for high- iv school graduates reporting no college, and $\vec{N}$ $3.7 \%$ for those reporting at least some college. $N$

Initiation in black adolescents is consider- 을 ably lower than in white adolescents (figure 3 ). $\vec{c}$ For whites, initiation first decreased and later $\frac{5}{5}$ increased, with the quadratic model $\left(P={ }^{\Phi}\right.$ $0.023)$ showing a better fit than the linear one 8 $(\mathbf{P}=0.092)$. For blacks, however, the linear. model was superior $(P=0.014$ compared with $\mathrm{P}=0.092$ for the quadratic). In 1989 , the initiation rate for whites was $6.0 \%$, in comparison with only $2.2 \%$ for blacks.

\section{CIGARETTE PRICE TREND}

Figure 4 shows the average price paid for a pack of cigarettes during the decade. The prices plotted have been adjusted by the CPI. Over the decade, the adjusted price per pack (in 1989 dollars) rose from $\$ 1.02$ to $\$ 1.44$, which was an increase of $40 \%$. From 1979 to 1984 , the percentage increase was $14 \%$, and from 1984 to 1989 , it was $23 \%$.

COMPONENTS OF TOBACCO MARKETING

The type of marketing activity emphasised as a percentage of the total advertising budget changed markedly during the decade (figure 5). In 1979, almost two thirds of tobacco marketing expenditures paid for print media. By 1989 , less than $25 \%$ of the total budget was allocated to that category. The percentage of $N$ the budget allocated to promotional allow- N ances increased from $12.7 \%$ of the total in N 1979 to $27.6 \%$ in 1989 . From 1979 to 1984 , the percentage increase in the portion of the budget devoted to these activities was $38.0 \%$, and this accelerated to $59.5 \%$ during the second half of the decade from 1984 to 1989 . The combined categories we designate as promotional items increased from $10.2 \%$ of the total in 1979 to $36.3 \%$ of the total in 1989 . The percentage increase was $100 \%$ from 1979 to 1984 and $77.9 \%$ from 1984 to 1989 .

\section{MARKETING AND INITIATION}

Figure 6 (right axis) shows the total marketing budget. From 1979 to 1984 the percentage increase in the total budget was $35.2 \%$, compared with $44.6 \%$ for the period from 1984 to 1989 , demonstrating an acceleration in total expenditures even after adjustment for 


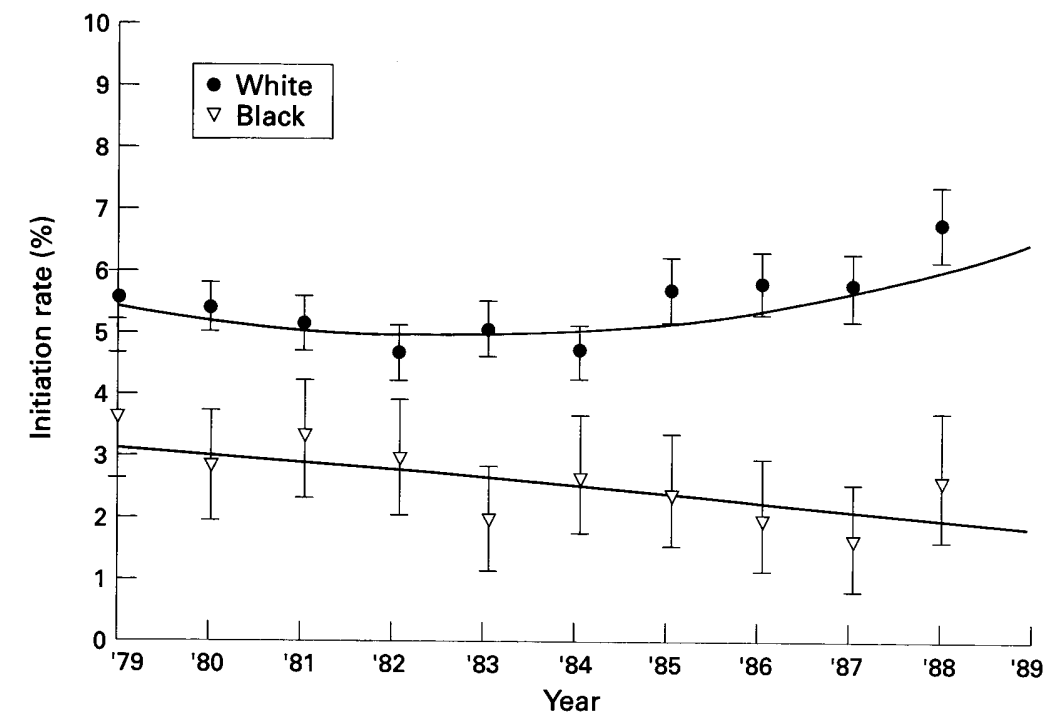

Figure 3 Initiation rates in white and black respondents aged 14-17 years.

inflation. The left axis of figure 6 shows the overall initiation among adolescents 14-17 years. Overall, the quadratic model fits the data better $(P=0.020)$ than the linear one $(P=$ $0.397)$. By 1989 , the initiation rate for adolescents reached $5.5 \%$, which was up from its lowest rate of $4.6 \%$ in 1982 and 1984; this was a nearly $20 \%$ increase compared with the $15 \%$ decline observed in the first part of the decade.

\section{Discussion}

In the early 1980 s, the rates of smoking initiation among both adolescents (aged 14-17 years) and young adults (aged 18-21 years) were decreasing. ${ }^{6}$ However, in mid-decade the downward trend was arrested only in adolescents, ${ }^{6}$ suggesting some change in the external influences for starting to smoke that may be specifically meaningful to adolescents, but not to young adults. Our analysis shows that the increase in initiation was particularly marked among male adolescents, white adolescents, and those who eventually did not graduate from high school.

There are a number of external factors that could potentially account for the increased initiation in adolescents. Some of these are difficult to measure, such as enforcement of laws regarding sales of cigarettes to minors, changes in the social image of smoking derived from peers, or changes in community norms regarding smoking, including preventive education. Certainly during the 1979 to 1989 decade, ever-increasing non-smoker activism and associated public education and awareness

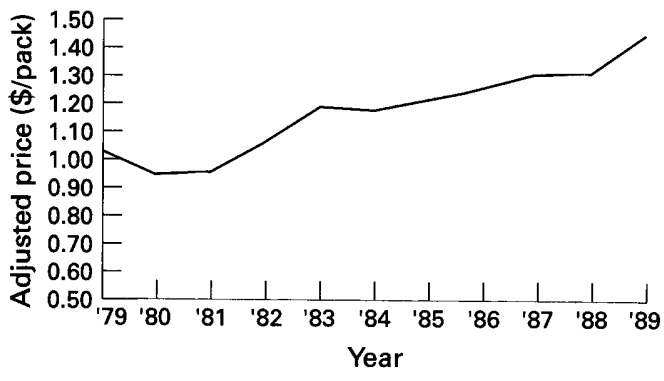

Figure 4 Price per pack of cigarettes adjusted by Consumer Price Index (CPI) to 1989 dollars. would have been expected to produce a downward trend in smoking initiation, as observed in young adults. ${ }^{6}$ It is not known whether it was these messages or other cultural influences that contributed to the continuing declme of smoking initiation among black बdolescents. Considerably lower smoking rates among black adolescents compared with whites have been documented previously. ${ }^{315}$ Rates of use of street drugs and alcohol among $\overline{\text { Tigh-school }}$ seniors declined during the decade, especially between 1985 and $1989 . .^{16}$ The game study showed that a decline in the prevalence of current smoking (use in the past 30 days) observed in the very early part of the decade was arrested in the latter part. ${ }^{16}$ If our study, we present data regarding cigaret price and tobacco marketing expenditures, aimd we comment below on how these factors might influence smoking uptake.

Some data indicate that adolesconts may be much more sensitive to pricing than young adults, with a price elasticity as high as -1.2 ; that is, each $10 \%$ increase in real cigarette price will be associated with a $12 \%$ decrease in adolescent smoking prevalence. ${ }^{217}{ }^{18} 8$ Thus, we could expect that the upswing in -aydolescentspecific initiation might be Otemporally associated with a downturn in ciga srette price. However, as the data of figure 5 in ficate, cigarette price (adjusted for inflation increased throughout the decade, which should have

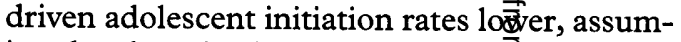
ing they bought their own cigarettes. Although experimentation usually occurs wi obtained from friends, or perhaps palfered from adults, by the time adolescents s\$aroke more than a few cigarettes a day, they afe probably buying their own. A recent Oosurvey of 13-16-year-olds, who are under the legal age for buying cigarettes in the Uni showed that $88 \%$ of daily smokers brought their own cigarettes, compared with only $41 \%$ of those who had smoked in the passt 30 days, but not daily. ${ }^{19}$

purchase

Perhaps adolescents had differegt purchase
practices in the early 1980 s, or pethaps their practices in the early 1980 s, or perthaps their
disposable income has increased. generic cigarettes were introduceg into the market in 1985, so it is possible that adolescents were strongly attractef to these alternatives to the premium brand a recent analysis has demonstrated that adolescents and young adults preferentially smoke premium cigarette brands, and that generic cigarettes are more popular among smokers over the age of 45 years, particularlythose with high levels of consumption. ${ }^{20}$ frus, it is unlikely that the price of cigarettes fan explain the turnaround in smoking initiation among adolescents that we have documented.

Other data associate tobacco ômarketing activity with adolescent smoking iptake. ${ }^{91-24}$ During periods when the tobacen industry sought to broaden their market by targeting particular groups with vigorous and novel marketing campaigns, initiation among youth increased. The first major cigarette marketing campaign of this century occurred in the 1910s, when RJ Reynolds launched the Camel 


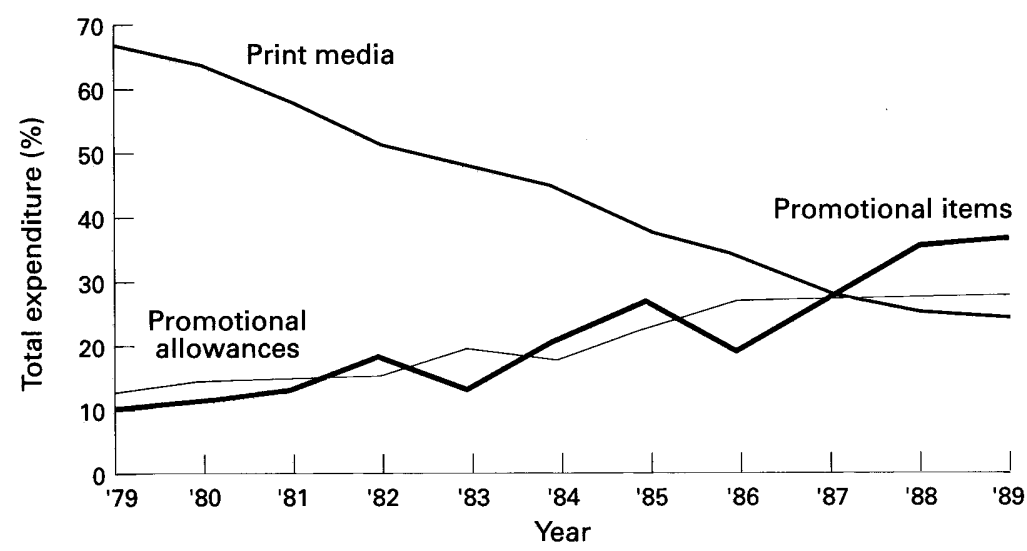

Figure 5 Percentage of total annual expenditures for different components of the tobacco industry marketing budget.

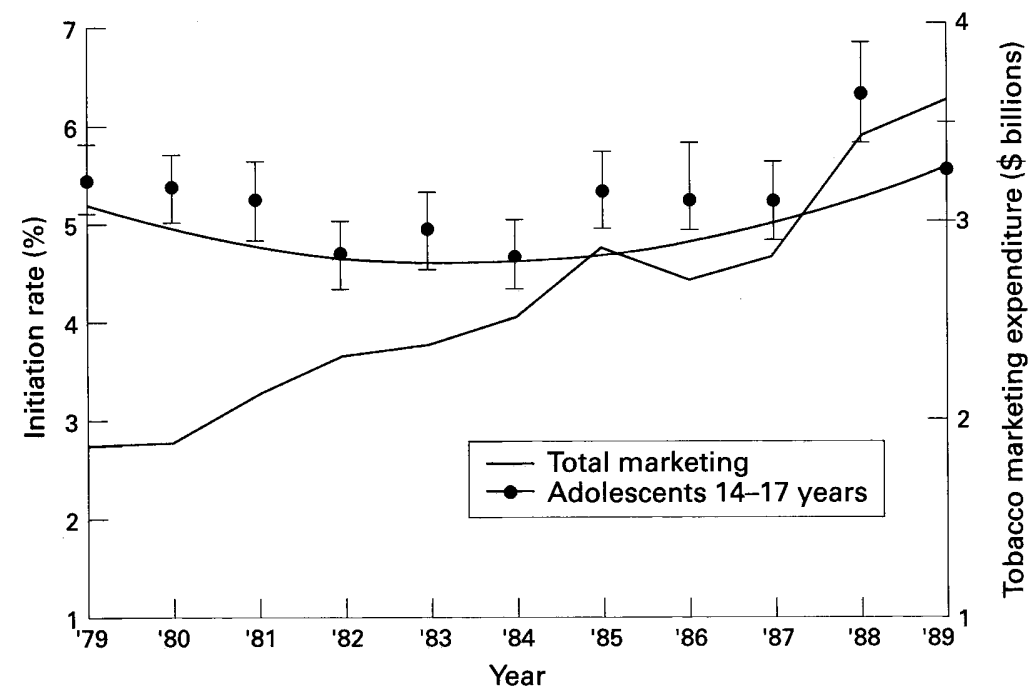

Figure 6 Left axis: initiation rates in adolescents aged 14-17 years; right axis: total tobacco marketing expenditures adjusted by Consumer Price Index (CPI) to 1989 dollars.

brand with an unprecedented marketing campaign. ${ }^{25}$ The brand quickly gained market leadership as sales soared, ${ }^{25}$ and initiation increased among both adolescent and young adult males. ${ }^{24}$ Females did not begin to take up smoking until the 1920s, when Lucky Strike and Chesterfield brands were pitched to women with such slogans as "Reach for a Lucky instead of a sweet" and "Blow some my way". As sales of these brands increased, ${ }^{26}$ so did initiation in adolescent and young adult females, but not males. ${ }^{24}$

Another period with a temporal association between increase in smoking initiation and tobacco marketing occurred between 1968 and 1973, when tobacco companies launched major advertising campaigns to introduce various new brands of cigarettes specially for women. ${ }^{1027}$ This time, however, initiation increased only among adolescent girls, whereas initiation in young adult females actually decreased. The advertising effect appears specific to adolescent females; young adult females apparently heeded the warnings about the health consequences of smoking. ${ }^{54}$ The tobacco industry commented that this correlation simply reflected the Zeitgeist of women's liberation, "the time when bra-burning women were abandoning traditional roles". ${ }^{28}$
During the 1980 s, the tobacco industry both increased the amount of its marketing budget and radically changed its marketing ap- $\bar{O}$ proaches (figures 5 and 6). The increase in the budget began shortly after the federal ban on cigarette advertising in the electronic media was implemented in 1971. But most of the

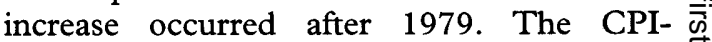
adjusted percentage increase in the total 0 budget from 1970 to 1978 was $44 \%$ or a yearly 흠 average of $5.5 \%$; from 1979 to 1989 , it was $\frac{\bar{s}}{7}$ $95.5 \%$ or a yearly average of $9.5 \%$. The decline $\stackrel{\mathbb{Q}}{\Omega}$ in smoking among adolescents in the late 1970 s and early $1980 \mathrm{~s}^{316}$ might have been even $\vec{\circ}$ greater if the industry had not increased its marketing expenditures. Given the history out- $\vec{\omega}$ lined above, it would be surprising if the acceleration in the rate of expenditures observed in $\stackrel{?}{\sigma}$ the 1980 s did not eventually contribute to the is reversal of the downward trend. When the data $\vec{N}$ become available, it is very likely that a further $N$ increase in smoking initiation by adolescents will be observed, and will corroborate recent $\overrightarrow{\vec{c}}$ reports documenting increased smoking prevalence. ${ }^{16}$

Changing marketing strategies also may have $\vec{\theta}$ played a role. Throughout the decade 1979 to 1989 , less emphasis was placed on print media. An interesting area for future research would be to characterise the placement of such advertisements. For example, are the remaining elaborate advertisements (multiple page or $\stackrel{\square}{\square}$ pop-up advertisements) more likely to appear $\overrightarrow{\vec{B}}$ in magazines with a substantial youth 3 readership? The increased emphasis on $\underset{F}{\vec{F}}$ promotional allowances, particularly in convenience stores where young children often $\overrightarrow{0}$ purchase sweets, ice cream and soft drinks, delivers the advertising message to these young customers even before adolescence. Finally, the promotional item component, especially coupon redemption (which is based on the air- 으 line industry's successful frequent flyer $\frac{0}{3}$ marketing programme), has had an impact on youth. ${ }^{29}{ }^{30}$ These programmes have escalated $\delta$ considerably since 1989 . A recent study showed that $10.6 \%$ of adolescents $12-17$ years 을 of age reported possession of a promotional $\frac{D}{O}$ item, and $35 \%$ either had an item, had collected coupons, or had a catalogue for such $N$ items. $^{29}$ In another school survey, $39.1 \%$ of $N$ high-school students had heard of Camel N Cash, $8.6 \%$ had used the cash, and $5.2 \%$ indi- $\sigma$ cated that they had bought cigarettes specifically to obtain the cash. ${ }^{30}$ It is unlikely that the industry would devote so much of its $\stackrel{\infty}{?}$ marketing resources to these activities if it did 0 not attract new smokers.

The question of why adolescents appear to $\stackrel{\square}{\overparen{D}}$ be vulnerable to tobacco marketing tactics $\stackrel{\mathbb{\Omega}}{\Omega}$ when adults (even young adults) are not may be related to the developmental stages that $\delta$ characterise adolescence. ${ }^{3}$ Adolescents sometimes seek to assert their independence with a symbol, such as a cigarette, which is associated with adulthood. Possession of a promotional item with a brand logo also provides such a symbol. In addition, adolescents are continuously seeking to define themselves as individuals and trying on various images. Tobacco 
advertising and promotions provide a multitude of such images: the tough independent, the slim sophisticate, the "party animal", and the sportsman or athlete (association of tobacco with the sponsorship of sporting events). Adolescents tend to live for the moment, to be self-indulgent, and to think of themselves as invulnerable; consequently, health warnings are not heeded. Tobacco companies have carried out considerable research on the young, and they have carefully characterised the traits mentioned above and the best methods for exploiting them. ${ }^{3}{ }^{31}$

The unprecedented scale of the recent expenditures for tobacco marketing and the increased emphasis on tactics that are particularly appealing to youth should be cause for national concern. Data from surveys conducted in California in 1993 and 1994 indicate that 12-17-year-old adolescents show as much interest in possessing promotional items as 18-24-year-old adults, although fewer adolescents actually own them. ${ }^{32}$ It is noteworthy that boys, white adolescents and those who report that their school performance is below average express more interest in having these items, and these groups are more likely to own them than girls, minorities, or those who rate their school performance as average or above. ${ }^{32}$ These findings, together with the historical data $^{1021-24}$ and the evidence from the present study, indicate that hypothesising a causal association between current tobacco marketing practices and the upward trends in adolescent initiation is reasonable.

This research was funded by the Robert Wood Johnson Foundation and the National Cancer Institute under contract NCI-CA72092. This work was completed during the tenure of Dr Pierce's Established Investigatorship from the American Heart Association.

1 Pierce JP, Fiore MC, Novotny TE, Hatziandreu EJ, Davis RM. Trends in cigarette smoking in the United States. Projections to the year 2000. $\mathscr{F} A M A$ 1989;261:61-5.

2 US Department of Health and Human Services. Reducing the health consequences of smoking: 25 years of progress. A report of the Surgeon General, 1989 . Rockville, Maryland:
Public Health Service, Centers for Disease Control, Office Public Health Service, Centers for Disease Control, Office
on Smoking and Health, 1989. (DHHS Publication No (CDC) 89-8411.)

3 US Department of Health and Human Services. Preventing tobacco use among young people. A report of the Surgeon General. Atlanta, Georgia: Public Health Service, Centers for Disease Control and Prevention, Office on Smoking and Health, 1994 (US Government Printing Office No S/N 017-001-00491-0.)

4 Pierce JP. Progress and problems in international public health efforts to reduce tobacco usage. Annual Rev Public Health 1991;12:383-400.

5 Gilpin EA, Lee L, Pierce JP. Smoking initiation rates in adults and minors: United States, 1944-1988. $A m \mathcal{F}$ Epidemiol 1994:140:535-43.

6 US Centers for Disease Control and Prevention. Trends in smoking initiation among adolescents and young adultsUnited States, 1980-1989. MMWR 1995;44:521-5.
7 US Federal Trade Commission. Federal Trade Commission report to Congress for 1993. Pursuant to the Federal Cigarette Labeling and Advertising Act. Washingto DC: Federal Trade Commission, 1995. Washingtg

8 Russell MAH. The nicotine trap: a 40-year छgntence for four cigarettes. Br F Addict 1990;85:293-300. O

9 Lee L, Gilpin EA, Pierce JP. Changes in the patterns of initiation of cigarette smoking in the Unit States: 1950 1965, and 1980. Cancer Epidemiol Biomarkers Prev 1993;2:593-7.

10 Pierce JP, Lee L, Gilpin EA. Smokire initiation by adolescent girls, 1944 through 1988. An-gssociation with targeted advertising. $\mathcal{F} A M A$ 1994;271:60\&-11.

11 Hansen RH. The current population surey: design and methodology. Washington, DC: US Depanment of Commerce, Bureau of the Census. July 1985 त्रechnical paper no. 40

12 The Tobacco Institute. The tax burden on cimarettes. Historical compilation. Washington DC: The Tobacco Institute,

1993: Vol. 28.
3 Bureau of Labor Statistics. <ftp://stats.bis.gov/pub/ time.series/cu>.

14 Larsen RJ, Marx ML, eds. An introduction $\overrightarrow{y_{j}}$ mathematical statistics and its applications, 2nd ed. Englewpod Cliffs, New Jersey: Prentice-Hall, 1986

15 Bachman JG, Wallace JM Jr, O'Mallef PM, et al. Racial/ethnic differences in smoking, driARing, and illicit drug use among American high school settiors, 1976-89. Am f Public Health 1991;81:372-7.

16 Johnston LD, O'Malley PM, Bachman $\mathrm{JG}_{\text {National survey }}$ results on drug use from the Monitoring thuture Study 1975-1992. Vol. 1: Secondary school students. US Department of Health and Human Services, Pukdic Health Service, National Institutes of Health, National Institute of Drug Abuse, 1994

17 US General Accounting Office. Teenage smoking. Higher excise tax should significantly reduce the number of smokers. Washington, DC: US General Accountife Office, 1989; GAO/HRD-89-119.

18 Lewit EM, Coate D, Grossman $M$. The effects of government regulation on teenage smokfig. 7 Law Econ government regulat

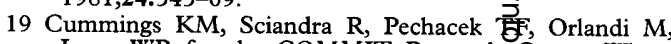
Lynn WR for the COMMIT ResearchoGroup. Where teenagers get their cigarettes: a survey of the purchasing habits of 13-16 years olds in 12 US comnunities. Tobacco Control 1992;1:264-7.

20 Cavin SW, Pierce JP. Low cost cigarette $\overrightarrow{\vec{Q}}$ and smoking behavior in California, 1990-1993. Am F Prev Med 1996; 12:17-21.

21 Pierce JP, Gilpin E, Burns DM, et al. Does acco advertising target young people to start smoking? Evidence from California. $\mathcal{F A M} A$ 1991;266:3154-8.

22 DiFranza JR, Richards JW Jr, Paulman $\mathrm{BM}$, et al. RJR Nabisco's cartoon camel promotes Camel cigarettes to children. $\mathcal{F} A M A$ 1991;266:3149-53.

23 Pierce JP, Gilpin EA. Looking for new customers among adolescents. Scientific Am 1995 May:50-5

24 Pierce JP, Gilpin EA. A historical analys of tobacco marketing and the uptake of smoking in the United States: 1890-1977. Health Psychol 1995;14:500-8

25 Tilley, NM. The Rf Reynolds Tobacco Compa曻y. Chapel Hill, North Carolina: University of North Caroma Press, 1985

26 Tennant RB. The American cigarette indugry. A study in economic analysis and public policy. New Homen, Connecticut: Yale University Press, 1950:88.

27 Jones KE. Women's brands: cigarette advepising explicitly directed toward women. Cambridge, Massachusetts: Harvard University Press, 1987.

28 Brody JE. Study ties women's brands to sinoking increase for girls. New York Times 1994 Feb 23.

29 Coeytaux RR, Altman DG, Slade J. Tobaccôpromotions in the hands of youth. Tobacco Control 1995;4:253-7.

30 Richards JW, DiFranza JR, Fletcher C, Fiscler PM. RJ Rey-

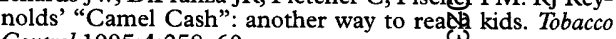
Control 1995:4:258-60.

31 Pollay RW, Lavack AM. The targeting of you marketers: Archival evidence on trial. Ads Consumer Res 1993;20:266-71.

32 Gilpin EA, Pierce JP, Rosbrook B. Are adolents receptive to current sales promotion practices of the tobacco industry? Prev Med 1997;26:14-21. 